\title{
O garoto selvagem: a importância das relações sociais e da educação no processo de desenvolvimento humano
}

\author{
Tatiane Marina dos Anjos Pereira* \\ Maria Terezinha Bellanda Galuch ${ }^{* *}$
}

\section{Resumo}

Partindo do pressuposto de que o processo de hominização ocorre na medida em que o indivíduo, vivendo em comunidade, se organiza sob as bases do trabalho, submetendo-se às leis sociais e históricas, o presente estudo analisa o filme francês O garoto selvagem (L'enfant sauvage), de 1969, cuja narrativa pauta-se na história verídica da descoberta, em 1797, de um garoto com idade entre 11 e 12 anos, que não demonstrava resquícios do contato com a sociedade humana. Considerando a relação que se estabelece entre os processos de desenvolvimento e aprendizagem, configurados numa situação incomum de total isolamento social, refletiu-se sobre as dificuldades e os avanços relatados pelo médico Jean Marc Itard, em relaçáo à reeducação do "garoto selvagem". Nesse sentido, a perspectiva histórico-cultural subsidiou a análise sobre o papel desempenhado pela educação nos processos de hominização e desenvolvimento cognitivo do garoto, ponderando as mudanças experimentadas por Victor, em meio às sucessivas tentativas de socialização impetradas por seu tutor. Anseia-se, assim, contribuir com as discussões fomentadas por autores como Banks-Leite e Galvão (2000a; 2000b); Gonçalves e Peixoto (2001); Dias (2007); Feijó (2007), entre outros. Palavras-chave: Desenvolvimento humano. Cultura. Educação.

\footnotetext{
* Mestre em Educação pela Universidade Estadual de Maringa (UEM/PR). Professora do Instituto Superior de Educação do Paraná (INSEP/PR).

** Doutora em Educação, na linha de pesquisa História, Política, Sociedade, pela Pontifícia Universidade Católica de São Paulo (PUC/SP). Professora do Departamento de Teoria e Prática da Educação e do Programa de Pós-Graduação em Educação Universidade Estadual de Maringa (UEM/PR).
} 


\section{Introdução}

Segundo Leontiev (2004), o consenso em relação à distinção entre homens e animais ultrapassou o caráter meramente biológico para se ancorar na compreensão do homem como "ser de natureza social". Dessa forma, o processo de hominizaçáo ocorre na medida em que o indivíduo, vivendo em comunidade, se organiza sob as bases do trabalho, submetendo-se às "leis sócio-históricas".

Tomando por base tais premissas, o presente artigo visa a refletir sobre o papel da interação social no processo de hominização, bem como o papel da educação no processo de desenvolvimento cognitivo. Para tanto, utilizar-se-ão as experiências narradas no filme "O garoto selvagem".

Acredita-se que as dificuldades e os avanços experimentados na tentativa de socialização do "selvagem de Aveyron" estão atrelados às concepçôes de desenvolvimento e aprendizagem adotadas pelo seu mentor, Jean-Marc Gaspard Itard. Todavia, não se pretende ignorar os atenuantes relativos às condiçôes materiais em que viveu até o momento em que foi achado por caçadores nos arredores dos bosques de Lacaune, ao sul da França.

Nesse sentido, a compreensão de desenvolvimento é um aspecto importante a ser considerado, principalmente porque Itard era um médico e não objetivava oferecer ao garoto uma formação escolar, ao menos não nos moldes atuais. Doravante se utilizará o termo "educação" para denotar a relação que se estabelece entre os processos de mediação que concorrem para o desenvolvimento cognitivo da criança, viabilizando o seu acesso às práticas e aos conhecimentos enraizados histórica e culturalmente.

Daí a importância em asseverar as experiências narradas por Itard, no intuito de discernir a relação que se estabelece entre os processos de desenvolvimento e de aprendizagem configurados numa situação incomum de total isolamento social.

\section{O garoto selvagem: a importância do convívio social}

O filme francês $O$ garoto selvagem (L'enfant sauvage), dirigido em 1969 por François Truffaut, tem duração de 88 minutos e narra a história de um garoto encontrado próximo à floresta de Aveyron. 
Baseado na história verídica do "Selvagem de Aveyron", o filme narra os acontecimentos relacionados à descoberta, em 1797, de um menino de idade entre 11 e 12 anos que vivia nos bosques, ao sul da França.

Vivendo como um animal selvagem, o garoto não sabia andar, falar ou expressar-se compreensivelmente, o que denotava o seu ínfimo contato com a raça humana, fato este que, posteriormente, reforçaria a tese de que o menino teria sido abandonado por seus progenitores com idade entre 4 ou 5 anos, tendo sido capaz de sobreviver e, ao mesmo tempo, sublimar quaisquer influências sociais que, porventura, houvesse recebido.

Tendo sido capturado, o garoto foi encerrado durante um mês no Asilo de Saint Afrique, destinado a doentes e indigentes, sem quaisquer cuidados ou observação mais apurada.

Nos meses subsequentes, o garoto ficou sob os cuidados do professor Bonaterre na Escola Central de Rodez, donde seria transferido, posteriormente, para o Instituto Nacional de Surdos-Mudos, sob a direção de Sicard, o qual constituiu uma comissáo composta por diversas profissionais, entre eles, o médico Philipe Pinel, cuja repercussão das observaçôes sobre o exótico garoto rendeu maior notoriedade.

Pinel concluiu que o garoto selvagem teria sido abandonado justamente por apresentar alto grau de demência, de modo a náo sugerir qualquer possibilidade de reabilitação e educação.

O filme enfatiza, no entanto, o empenho do jovem médico JeanMarc Gaspard Itard, curiosamente discípulo de Pinel, em angariar a guarda do garoto e comprovar a sua teoria de que o menino selvagem poderia ser educado e reintegrado à sociedade, já que, a seu ver, ele tão-somente carecia do convívio social e de métodos particulares para desenvolver suas capacidades humanas.

Conforme destaca Feijó (2007), as metas pedagógicas de Itard consistiam em promover situaçóes que motivassem, entre outros aspectos, o interesse pela vida social, a sensibilidade nervosa, o uso da fala e as operaçóes mentais. Nesta perspectiva, o vídeo retrata as observaçóes, os experimentos, os avanços e os obstáculos enfrentados por ele nesta árdua empreitada.

Com a ajuda de sua governanta, Madame Guérin, Itard demonstra, não sem esforços e constantes dificuldades, que o garoto selvagem de Aveyron, ao qual nomeou Victor, possuía capacidades intelectuais e biológicas passíveis de 
desenvolvimento, na medida em que respondia, embora vagarosamente, aos métodos e experimentos realizados na tentativa de socialização do menino.

Considerando tais experimentos, qual a relaçáo entre o processo de hominização exposto por Leontiev (2004), um dos principais teóricos da Psicologia histórico-cultural, e os progressos no desenvolvimento (afetivo, cognitivo e social) de Victor? É possível inferir o papel da educação nesse processo?

Partindo-se do pressuposto apresentado por Leontiev (2004) de que os homens, desde o desenvolvimento do Homo sapiens, já detêm todas "[...] as propriedades biológicas necessárias ao seu desenvolvimento sócio-histórico ilimitado" (LEONTIEV, 2004, p. 281), o que se pode concluir acerca das dificuldades encontradas por Victor para se adequar à vida em sociedade?

Tendo em vista que a abordagem histórico-cultural enfatiza, em relação ao desenvolvimento psicológico e os processos de aprendizagem, que as transformações qualitativas na história do sujeito, tanto quanto na história da humanidade como um todo, estão intrinsecamente relacionadas aos modos culturais de ordenação do pensamento, especialmente no que concerne às funçôes psicológicas superiores, tipicamente humanas, pode-se compreender a importância dos estudos realizados por Itard no processo de socialização de Victor, embora o filme se concentre somente nos primeiros nove meses do trabalho desenvolvido por ele.

Itard acreditava que, em Victor, poder-se-ia estimar o grau de inteligência de um adolescente privado da convivência humana, o que o motivou a persuadir os que supunham a demência do garoto, como evidencia o trecho das suas anotaçóes, disponibilizada nos estudos de Gonçalves e Peixoto (2001):

Se me fosse dado resolver este problema de metafísica: determinar qual seria o grau de inteligência e a natureza das ideias dum adolescente que, privado desde a sua infância de qualquer educação, tivesse vivido completamente separado dos individuos da sua espécie, enganar-me-ia grosseiramente, ou a solução do problema reduzir-seia a estipular que esse indivíduo tem uma inteligência relativa ao pequeno número das suas necessidades e despojada, por abstracção, de todas as ideias simples e complexas que recebemos pela educação e que se combinam no nosso espírito de tantas maneiras, apenas 
pelo meio do conhecimento dos sinais. Pois bem, o quadro moral deste adolescente seria correspondente ao do Selvagem de Aveyron e a solução do problema daria a medida e a causa do seu estado intelectual. (ITARD, 1801 apud GONÇALVES; PEIXOTO, 2001, p. 73, grifos do autor).

A hipótese de Itard acerca da influência social no desenvolvimento cognitivo era inovadora, sobretudo ao considerar que os primeiros esboços da ideia da evolução sócio-histórica da mente foram delineados somente a partir da segunda metade do século dezenove, com os estudos de Charles Darwin, conforme pontua Luria (2008). Essa análise também é desenvolvida no texto de Feijó (2007), na medida em que relaciona o contexto da Revolução Francesa ao aparecimento de Victor e, posteriormente, aos estudos de Darwin, que incrementariam as discussóes sobre as origens da inteligência, como fruto da evolução ou do ambiente.

$\mathrm{Na}$ metodologia de ensino de Itard, as necessidades biológicas primárias de Victor impulsionavam o seu aprendizado. Verifica-se, assim, um processo muito comum à evolução da espécie humana (filogênese), na medida em que os sentidos se desenvolvem em consonância às necessidades e aos prazeres primitivos, dinamizando um desenvolvimento que transcende os aspectos físicos:

[...] a conexão íntima que liga o homem físico ao homem intelectual, dado que, embora os seus domínios pareçam e sejam, efectivamente, muito distintos, tudo se confunde nos limites em que se tocam essas duas ordens de funçóes. O seu desenvolvimento é simultâneo e a sua influência recíproca. Deste modo, embora dedicasse os meus esforços a exercitar os sentidos do nosso selvagem, o espírito tomava a sua parte dos cuidados exclusivamente dados à educação desses órgãos e seguia a mesma ordem de desenvolvimento. Concebe-se, com efeito, que ensinando os sentidos a percepcionar e distinguir novos objectos, forcei a atenção a deter-se nos mesmos, o juízo a compará-los e a memória a retê-los. (ITARD, 1801 apud GONÇALVES; PEIXOTO, 2001, p. 86). 
Além disso, o convívio social de Victor, embora ainda limitado, suscitou no adolescente novas necessidades: materiais, físicas, biológicas, intelectuais e afetivas, de modo a, lentamente, torná-lo capaz de exercer operaçóes simples em relação aos objetos próprios às suas interpelaçôes humanas.

Assim, pode-se auferir, por meio das experiências relatadas, que o desenvolvimento cognitivo de Victor, embora muito afetado pelas condições de vida a que estivera submetido, seguiu alguns direcionamentos comuns à formaçáo humana e intelectual de uma criança que ingressa no seio de uma comunidade social.

Não obstante as dificuldades encontradas por Itard no processo de reeducação de Victor, a valorização das características e necessidades individuais, como ponto de partida para a apropriação das práticas sociais cristalizadas, merece destaque.

Vale lembrar que a apropriação, segundo Leontiev (2004, p. 290), resulta de "[...] uma atividade efetiva do indivíduo em relação aos objetos e fenômenos do mundo circundante criados pelo desenvolvimento da cultura humana". Da mesma forma, Vygotsky (2003) assevera a importância da apropriação das atividades socialmente enraizadas e historicamente construídas como fator característico da psicologia humana, aspecto igualmente assinalado por Leontiev (2004):

O desenvolvimento mental da criança é qualitativamente diferente do desenvolvimento ontogênico do comportamento nos animais. Esta diferença provém, sobretudo, da ausência nos animais de um processo essencial no desenvolvimento da criança: o processo de apropriaçáo da experiência acumulada pela humanidade ao longo de sua história social. (LEONTIEV, 2004, p. 339-340).

Daí a inferência da relação entre o processo de hominização de Victor e os progressos no seu desenvolvimento afetivo, cognitivo e social. De fato, "[...] a apropriação da cultura humana dá origem às formas especiais de conduta, modifica a atividade das funçôes psicológicas superiores e cria novos níveis de desenvolvimento humano" (DIAS, 2004, p. 6).

Com a intervenção de Itard, Victor iniciou a transição do homem primitivo para o homem cultural (hominização). Contudo, o processo de 
humanização, que caracteriza o sujeito na apropriação da herança cultural da humanidade, ainda parecia distante.

$\mathrm{Na}$ medida em que Itard promovia situaçóes em que houvesse a necessidade de interação entre Victor e as pessoas que o circundavam, o menino apropriava-se de alguns instrumentos, mas ainda não se apoderava da prática social enraizada em tais objetos. Foi o que ocorreu com o uso dos talheres, das roupas, calçados e, particularmente, da xícara, relacionada sempre ao gosto que adquiriu pelo leite. Associados às necessidades físicas e biológicas do menino, esses objetos angariaram um significado social, embora ainda destoassem de um nível de desenvolvimento que propiciasse a formação e o uso da consciência.

Sob esse prisma, é importante resgatar alguns conceitos da teoria históricocultural acerca do desenvolvimento da consciência.

Leontiev (2004) assinala que o aparecimento da consciência indica um nível mais elevado na escala da formação psíquica do ser humano, caracterizado pela capacidade que o indivíduo desenvolve em distinguir as propriedades objetivas da realidade de seu mundo subjetivo, ou seja, de seus sentimentos e impressóes. É o que Leontiev (2004) denomina "reflexo psíquico da realidade".

Luria (2008), ao conceituar alguns princípios da psicologia soviética acerca do desenvolvimento da consciência como algo que não se forma intrínseca e naturalmente, assevera que os processos mentais estáo sujeitos às práticas sociais, resultando da atividade humana que se renova constantemente e modifica a natureza:

O modo pelo qual as formas da atividade mental humana historicamente estabelecidas se correlacionam com a realidade passou a depender cada vez mais de práticas sociais complexas. Os instrumentos usados pelos homens em sociedade para manipular o ambiente, além de produtos de geraçôes anteriores que ajudam a formar a mente da criança em desenvolvimento, também afetam essas formas mentais. Na criança em desenvolvimento, as primeiras relaçóes sociais e as primeiras exposiçôes a um sistema lingüístico (de significado especial) determinam as formas de sua atividade mental. (LURIA, 2008, p. 23).

No caso de Victor, por ter sido privado da convivência humana, sua atividade ainda estava atrelada à própria sobrevivência, de modo que a realidade 
se configurava uma extensão de suas impressōes pessoais; sua relação com a natureza era táo instintiva quanto a de qualquer outro animal, e o objeto de sua atividade confundia-se constantemente com o seu motivo biológico.

Sobre isso, discorre Leontiev (2004) ao asseverar que, no homem, o elo existente entre o objeto e o motivo de uma ação reflete relaçóes e ligações objetivas sociais, e não naturais, como acontece com os animais primitivos. Essa sujeição da atividade humana às relaçôes sociais é o que dá origem, segundo o autor, à "[...] forma especificamente humana do reflexo da realidade, a consciência humana" (LEONTIEV, 2004, p. 85), isto é, a capacidade do homem de refletir psiquicamente sobre a ligação entre o objeto e o motivo de sua ação.

Podemos perceber alguns desses aspectos nas açóes que Victor empreende para realizar a atividade de tomar leite: ao buscar a tigela ou tentar abrir o armário para pegar a taça e, então, apresentá-la a um adulto para ganhar leite, Victor confunde o objeto da ação (o seu fim), ou seja, ganhar o leite, ao seu motivo (aspecto gerador da atividade), que é se saciar, ou seja, essa relação entre pegar a taça, apresentar a um adulto e ganhar o leite tem, para Victor, o significado biológico do alimento. Não se constitui, portanto, uma atividade racional e planejada, ao contrário, é o resultado de açóes mecânicas e condicionadas.

Outro fator importante ressaltado por Leontiev (2004) éa correspondência, no âmbito da consciência, entre o significado social e o sentido pessoal da ação, o que também não se faz presente na atividade de Victor. Isso se dá, porque o objeto não assume o caráter de instrumento; não há a ideia, o pensamento que fundamenta o uso do objeto, ou seja, não há uma função enraizada socialmente no objeto que o caracterize como instrumento. A tigela, para Victor, serve à finalidade única de receber o leite, o que indica a falta de consciência da finalidade da ação atrelada à incapacidade de analisar e generalizar as propriedades objetivas do objeto, de modo que ele não compreende que o mesmo objeto pode ser utilizado de outras formas e para outros fins.

Esse processo também pode ser verificado na relação mecânica e irracional que o menino estabelece com outros objetos e algumas palavras escritas. Em alguns momentos, o menino tem acessos de fúria, mediante algumas açôes que lhe são solicitadas por Itard em seu processo de alfabetização. $\mathrm{O}$ menino não vê sentido em conhecer, nominar, ler algumas palavras e objetos, pois tais açôes estão relacionadas unicamente à compensação de beber água. Não há, portanto, uma operação mental relacionada aos objetos e às ações requeridas. 
E, segundo Leontiev (2004, p. 90), “[...] é condição necessária do aparecimento do pensamento a distinçáo e a tomada de consciência das interaçóes objetivas. Mas esta tomada de consciência é impossível nos limites da atividade instintiva dos animais".

Sob essa premissa é, pois, compreensível, a estagnação das capacidades intelectuais de Victor, uma vez que ele foi privado, desde a mais tenra idade, da mediação dos instrumentos e signos próprios à intervençáo da cultura humana, o que acarretou consequências ímpares em sua formaçáo.

É importante, também, considerar a possibilidade de que o menino tivesse algum tipo de deficiência física ou intelectual que, somado ao seu modo privado de vida, tenha dificultado o seu aprendizado.

Outra explicação plausível é que a metodologia de ensino utilizada por Itard não tenha sido suficiente para promover um desenvolvimento cognitivo satisfatório. Pautada em técnicas de reforço positivo, punição e atividades mecânicas, a pedagogia empreendida pelo médico não favoreceria acentuados progressos.

Além disso, o contato de Victor com a sociedade era insuficiente, sua convivência restringia-se ao jovem médico, à Madame Guérin e a alguns vizinhos que, periodicamente, visitavam. $\mathrm{O}$ menino já demonstrara sua dificuldade de interaçáo com outras pessoas e preferia a solidão ao caos da multidão, mas isso era compreensível, dadas as circunstâncias em que foi tirado da floresta, enclausurado na prisão de Rodez e, posteriormente, despejado no colégio de surdos-mudos, no qual demonstrou grande insociabilidade, tendo sido maltratado por outras crianças e explorado por guardas que o expunham à população como um espetáculo exótico.

Ademais, o náo-desenvolvimento da fala impediu Victor de convergir a linguagem à atividade prática, afetando consideravelmente a construção do pensamento e o seu progresso intelectual; esse é outro fator importante a ser considerado no processo de desenvolvimento de Victor, sobretudo quando se considera o exposto por Leontiev (2004, p. 92): a linguagem "[...] torna-se a forma e o suporte da generalização consciente da realidade".

Segundo Dias (2007), é a comunicação, suscitada pela interação social, que possibilita à criança se apropriar dos objetos humanos com os quais reproduz as açôes humanas. 
De fato, Vygotsky (2003) assegura o papel da linguagem no processo de desenvolvimento intelectual:

Antes de controlar o próprio comportamento, a criança começa a controlar o ambiente com a ajuda da fala. Isso produz novas relaçôes com o ambiente, além de uma nova organização do próprio comportamento. A criação dessas formas caracteristicamente humanas de comportamento produz, mais tarde, o intelecto [...]. (VYGOTSKY, 2003, p. 33).

Sobre esse assunto, também discorre Oliveira (2008) ao refletir as ideias preconizadas por Vygotsky acerca da linguagem como um sistema simbólico que atua como mediador nos processos psicológicos superiores, próprios do ser humano. Destarte, os elementos mediadores, instrumentos e signos, introduzem uma nova ligação na relação entre o homem e o meio, de modo que, no curso do desenvolvimento humano, as relaçôes mediadas prevaleçam sobre as relações diretas.

O conceito de instrumento está relacionado, segundo Oliveira (2008), à atividade coletiva (trabalho) e à consequente transformação da natureza, em cuja dinâmica se formam a cultura e a história da humanidade. É, portanto, um mediador externo que encerra em si uma determinada prática social.

Já os signos constituem-se auxiliares internos que mediam as ações psicológicas do indivíduo, permitindo ao homem representar mentalmente objetos e situaçóes da realidade, sendo apropriados pelo homem por meio das interaçóes sociais com outros membros da comunidade e com elementos do ambiente social. Segundo Oliveira (2008), as experiências vivenciadas no contato com o mundo culturalmente estruturado permitiráo ao sujeito elaborar seu sistema de signos que, por sua vez, mediará sua forma de interpretar e organizar a realidade.

Considerando que esses elementos mediadores provêm das relaçóes sociais, a linguagem serve tanto à comunicação entre os homens quando ao ordenamento do real, tal qual explicita Oliveira (2008). O pensamento generalizante exprime, portanto, a capacidade humana de classificar e organizar o mundo concreto de acordo com categorias conceituais, tornando a linguagem um instrumento do pensamento. 
No caso de Victor, pode-se depreender que a sua comunicação se delineava, em princípio, no campo da inteligência prática, não assumindo, ainda, a função de signo.

Oliveira (2008), ao resgatar o pensamento de Vygotsky acerca do desenvolvimento filogenético, lembra que há um momento na evolução humana em que o pensamento se torna verbal, e a linguagem, racional. Todavia, essa associação só ocorre após a fase a pré-linguística do pensamento e a fase préintelectual da linguagem. É o que permite às crianças utilizarem a inteligência prática para resolver pequenos problemas do cotidiano, uma vez que a sua interação com o mundo ainda não é mediada pela linguagem.

Itard soube reconhecer a importância da fala no processo de percepção e representação dos objetos. Contudo, nas atividades propostas para Victor, tal percepção não ultrapassava seu campo visual e, embora relacionasse a fala à resposta de suas necessidades, pouco avançou no desenvolvimento da linguagem. Por certo, as perdas inerentes aos aproximados 5 a 6 anos distantes do convívio social acarretaram-lhe danos consideráveis.

Ademais, após ter vivido tantos anos completamente isolado, impedido de conhecer e utilizar a linguagem como signo, as atividades educativas desenvolveram em Victor, primeiramente, a inteligência prática. Daí a dificuldade de Victor em relacionar palavras e sons aos objetos. No campo visual, o garoto reconhecia alguns instrumentos, mas essa percepçáo não lhe permitia, ainda, pensar ou generalizar tais objetos. Suas manifestaçóes verbais resumiam-se, portanto, aos grunhidos que emitia e, ocasionalmente, ao choro.

Os progressos e retardos de Victor delineiam claramente as concepções de Vygotsky sobre a evolução da espécie humana (filogênese) e do próprio indivíduo (ontogênese).

Assim, a "educação de Victor", segundo as etapas definidas por Itard, refletem a socializaçáo e consequente sensibilização do sistema nervoso pelo estímulo iminente a fim de cultivar a transformação das atividades primitivas e adequá-las culturalmente.

Posteriormente, Itard, visando a canalização da atenção e da percepção de Victor, serve-se de jogos e objetos cujas respostas atendem proeminentemente às suas necessidades primárias, especialmente digestivas, de modo a, gradativa e insensivelmente, conforme pondera J. M. Itard, elevar a complexidade dos jogos e atividades no intuito de desenvolver-lhe as capacidades cognitivas. 
A esta altura, o fato de Victor não desenvolver a fala, atendo-se sempre aos sons desconexos, representou um agravante no processo traçado por Itard, embora este tenha considerado a rigidez que a sensibilidade auditiva havia adquirido nos anos de isolamento social que vivenciara, quando da determinaçấo de seus resultados pedagógicos, especialmente porque o jovem médico acompanhava a formaçáo dos surdos-mudos, sendo capaz de compreender a dificuldade de se estabelecerem representaçôes simbólicas sem quaisquer estímulos e possibilidade para tal nos primeiros anos de vida.

A incapacidade de falar de Victor estava atrelada à sua predisposição orgânica, ou seja, o método supunha as condiçôes biológicas, até então completamente atrofiadas. No entanto, embora o médico tenha buscado criativamente sempre novos métodos, seu insucesso foi notoriamente registrado em suas memórias e, ao que consta, perdurou até a morte de Victor, aos 40 anos em 1828.

Durante o tempo em que permaneceu sob os cuidados especiais de Itard, Victor progrediu paulatinamente. Entretanto, conforme apontam os estudos de Banks-Leite e Galvão (2000a; 2000b), nos dez anos subsequentes, vividos no Instituto de Surdos-Mudos, poucos avanços foram obtidos, de modo que sua guarda foi concedida em definitivo à Madame Guérin, com quem permaneceu até 1828, nos últimos 20 anos de sua vida. Segundo as autoras, o último relato sobre Victor, datado de 1817, afirmava que ele permanecia atemorizado, semisselvagem e afásico.

\section{Considerações finais}

Tendo em vista que a abordagem histórico-cultural pondera a estreita relação entre aprendizado e desenvolvimento, a evolução de Victor demonstra que Itard reconhecia tal ligação, embora a teoria vygotskyana tivesse surgido muito tempo depois.

Por certo, Jean-Marc Itard compreendeu o aprendizado como prérequisito ao desenvolvimento de Victor, motivo pelo qual incessantemente elaborou métodos e experimentos a fim de propiciar ao jovem meios para suprir as deficiências físicas e cognitivas que experimentara durante os primeiros anos de sua vida.

Ademais, a pedagogia de Itard conferiu às operaçóes concretas e à acuidade visual de Victor os objetivos peculiares às suas necessidades físicas e, 
posteriormente, à sua instrução. Neste contexto, há de se ressaltar o exemplo paradoxal do aprendizado do "jovem selvagem" e os procedimentos adotados por Itard.

Destaca-se a importância dos estudos e experimentos realizados na reeducação do garoto selvagem, pois favorecem a compreensão da abordagem histórico-cultural, uma vez que contextualizam a relevância das relaçóes sociais no processo de aprendizagem e desenvolvimento da criança, especialmente no que diz respeito à formação das funçóes psicológicas superiores, que nos caracterizam como seres humanos.

Nesse sentido, o processo de hominização de Victor, prejudicado pela privação do convívio humano, permitiu-lhe que se sentisse parte do mundo civilizado, mas não lhe conferiu um modo de vida, de fato, afeito à sociedade, até porque isso é papel da educação, tanto pré-escolar quanto escolar.

Depreende-se, ainda, que o aprendizado propiciado pelos métodos de Itard, embora auxiliassem no processo de hominização de Victor, pouco representaram no âmbito do desenvolvimento intelectual, já que suas finalidades pedagógicas se alinhavam unicamente aos objetivos de socialização. Assim, os conhecimentos apreendidos por Victor restringiam-se à aplicabilidade prática de objetos e palavras.

Aí está a implicação pedagógica das experiências de Itard. Mesmo reconhecendo que outros fatores possam ter influenciado o processo educativo de Victor, entre os quais, uma possível deficiência intelectual ou física, como já ressaltado anteriormente, não se pode afirmar que houve um processo de humanização que permitisse a Victor apreender a cultura humana material e intelectual, uma vez que "[...] as aquisiçôes do desenvolvimento histórico das aptidóes humanas não são simplesmente dadas aos homens nos fenômenos objetivos da cultura material e espiritual que os encarnam, mas são aí apenas postas" (LEONTIEV, 2004, p. 290, grifos do autor).

Segundo Leontiev (2004), essas aquisiçóes da cultura humana só podem ser transmitidas às novas geraçoóes por meio da educação, e isso sugere condições uniformes, o que não ocorre devido às desigualdades sociais que incidem sobre o processo educativo da humanidade. No caso de Victor, ainda há o atenuante do isolamento quando se consideram as suas perspectivas de desenvolvimento.

Esse fator se torna fundamental, quando se pondera a ideia do espaço ocupado pela criança no ambiente social como pressuposto ao seu desenvolvimento cognitivo, como assevera Luria (2006). 
Victor não vivenciou o período pré-escolar, ou seja, o momento no curso do desenvolvimento infantil em que as crianças se abrem ao mundo, ocupando um espaço social definido segundo as relaçóes que estabelecem com os seus familiares e outros indivíduos. Nessa fase, a criança ultrapassa a manipulação de objetos e passa a assimilar a realidade que a circunda, reproduzindo, por meio de atividades e jogos, as açôes humanas. $\mathrm{O}$ menino selvagem sequer teve suas necessidades vitais supridas, como normalmente ocorre nessa fase, cujos sentimentos de dependência e segurança permitem formar os círculos sociais íntimos que, doravante, prepararâo a criança para a reestruturação que seu papel social sofrerá no ambiente escolar.

Para Victor, a fase escolar não significou a tomada de consciência de um novo papel social e da realização de seus deveres em relação à sociedade, na qual, segundo Luria (2006), reside o conteúdo de toda a vida futura.

Outro aspecto importante, relatado por Vygotsky (2003), é a compreensão da relaçáo existente entre desenvolvimento e aprendizagem, que incide sobre as finalidades pedagógicas e as metodologias de ensino.

Nesse sentido, Vygotsky (2005) salienta que, embora haja uma relação indiscutível entre o "nível de desenvolvimento e a capacidade potencial de aprendizagem" da criança, há que se atentar tanto para o nível de desenvolvimento efetivo (real), quanto para a zona de desenvolvimento proximal; o primeiro define "funçóes que já amadureceram, ou seja, os produtos finais do desenvolvimento", enquanto a zona de desenvolvimento proximal permite vislumbrar aquilo que ainda "está em processo de maturação". Esses dois níveis podem auxiliar um diagnóstico mais preciso acerca do nível de desenvolvimento intelectual da criança, possibilitando estabelecer métodos mais eficazes de intervenção pedagógica.

Outrossim, a hipótese de Vygotsky (2003) de que há uma coesão, e não propriamente uma uniformidade entre os processos de desenvolvimento e aprendizagem, evidencia a importância de se refletir, pesquisar e discernir o modo como o conhecimento e as capacidades humanas são internalizados pelo indivíduo.

Provavelmente, os rumos educacionais de Victor seriam diferentes, se naquela época tais ideias já fizessem parte das altercaçóes sobre o processo de ensino-aprendizagem. O fato é que as propriedades biológicas de Victor, embora pudessem promover o seu desenvolvimento sócio-histórico ilimitado, tal qual preceitua Leontiev (2004), careciam da experiência sociocultural, 
mola propulsora de todo o processo de humanização e, consequentemente, do desenvolvimento das capacidades propriamente humanas. Houve, portanto, uma inversão de etapas, que se configurou um empecilho ao próprio processo de socialização, que, ao invés de ser o elemento fundante da formação humana e intelectual de Victor, se tornou a finalidade do processo de aprendizagem, comprometendo todo o seu processo de humanização e desenvolvimento cognitivo.

E já que o "[...] indivíduo aprende a ser um homem" (LEONTIEV, 2004, p. 285), é função da educação perpetuar o movimento das geraçóes, transmitindo aos homens a cultura acumulada, histórica e socialmente.

Ora, isso é possível na medida em que o sujeito se torna capaz de apreender a cultura humana, servindo-se dos instrumentos físicos e simbólicos, como a linguagem, para apropriar-se de conceitos cotidianos e, principalmente, científicos. Esse processo só é possível quando a organização do ensino favorece o pensamento abstrato ou conceitual, uma possibilidade totalmente distante dos processos de ensino e aprendizagem disponibilizados a Victor, não só por razóes metodológicas, mas também por fatores biológicos e psicológicos, inerentes às condiçôes de vida do garoto.

De qualquer forma, as experiências relatadas por Itard, bem como as dificuldades e alguns avanços percebidos no processo de desenvolvimento de Victor, permitem auferir algumas possibilidades de intervenção pedagógica mais precisas, sobretudo quando se considera a importância do pensamento conceitual como condição essencial à formação do homem. Em síntese, uma aprendizagem que visa a promover o desenvolvimento intelectual requer que os conhecimentos apropriados, na medida em que são processados e transformados em instrumentos simbólicos, façam a mediação entre o indivíduo e a realidade social.

Por certo, como acentuam Banks-Leite e Galvão (2000a), os relatos de Itard não servem somente à compreensão histórica sobre a articulaçáo de um projeto educativo particular, mas também contribuem para discussóes atuais que, na esfera educacional, envolvem concepçôes e métodos pedagógicos.

Ponderando os pressupostos da teoria histórico-cultural, almeja-se que as reflexôes empreendidas neste artigo contribuam para a análise da prática educativa, a fim de que os objetivos do processo de aprendizagem não se restrinjam à socialização, em detrimento de um desenvolvimento cognitivo que permita ao sujeito realizar açóes conscientes, servindo-se do pensamento 
abstrato. Não se trata, enfim, de promover uma organização de ensino pautada em saberes com aplicabilidade prática, e sim em conceitos científicos, úteis e necessários à representação menos superficial e alienante da realidade.

\section{REFERÊNCIAS}

O GAROTO Selvagem. Produção de Marcel Berbert. França: Les Productions Artistes Associes, 1969. 1 videocassete (88 min).

BANKS-LEITE, Luci; GALVÃO, Izabel. A educação de um selvagem: as experiências pedagógicas de Jean Itard. São Paulo: Cortez, 2000a.

BANKS-LEITE, Luci; GALVÃO, Izabel. Jean Itard e Victor de Aveyron: uma experiência pedagógica do século XIX e suas repercussóes. In: CONFERÊNCIA DE PESQUISA SOCIOCULTURAL, 3, 2000. Anais... Campinas: Unicamp, 2000b. Disponível em: <http://www.fae.unicamp.br/ br2000/trabs/1750.doc>. Acesso em: 12 fev. 2011.

DIAS, Lucyanne Cecília et al. A interação social e a cultura no processo de desenvolvimento psíquico do menino selvagem de Aveyron. In: CONGRESSO INTERNACIONAL DE PSICOLOGIA, 3., 2007, Maringá. Anais... Maringá: Universidade Estadual de Maringá, 2007, p. 1-9. FEIJÓ, Martin C. O Garoto Selvagem em três tempos: Victor de Aveyron e uma história cultural da inteligência. FACOM, São Paulo, n. 18, p. 4-11, 2007. Disponível em: <http://www.faap.br/revista_faap/revista_facom/ facom_18/martin.pdf $>$. Acesso em: 20 jan. 2011.

GONÇALVES, Jorge; PEIXOTO, Maria A. O menino selvagem: estudo do caso de uma criança selvagem retratado no filme "O menino selvagem" de François Truffaut. Lisboa: Universidade de Lisboa, 2001. Disponível em: <http://www.educ.fc.ul.pt/docentes/opombo/cinema/dossier/ meninoselvagem.pdf>. Acesso em: 15 fev. 2011.

LEONTIEV, Alex N. O desenvolvimento do psiquismo. Tradução Rubens Eduardo Frias. São Paulo: Centauro, 2004.

LURIA, Alexander Romanovich. Desenvolvimento cognitivo: seus fundamentos culturais e sociais. São Paulo: Ícone, 2008.

LURIA, Alexander Romanovich. Diferenças culturais de pensamento. In: VYGOTSKY, Lev Semenovich; LURIA, Alexander Romanovich; 
LEONTIEV, Alex N. Linguagem, desenvolvimento e aprendizagem. Tradução de Maria da Penha Villalobos. São Paulo: Ícone, 2006, p. 39-58.

OLIVEIRA, Marta Kohl. Vygotsky. Aprendizado e desenvolvimento: um processo sócio-histórico. São Paulo: Scipione, 2008.

VYGOTSKY, Lev Semenovich. A formação social da mente: o desenvolvimento dos processos psicológicos superiores. São Paulo: Martins Fontes, 2003.

VYGOTSKY, Lev Semenovich. Aprendizagem e desenvolvimento intelectual na idade escolar. In: LURIA, Alexander Romanovich et al. Psicologia e Pedagogia I: bases psicológicas da aprendizagem e do desenvolvimento. Tradução de Rubens Eduardo Frias. São Paulo: Centauro, 2005, p. 25-42. 


\section{El niño salvaje: la influencia de la interacción social y el papel de la educación en el proceso de desarrollo cognitivo}

\section{Resumen}

Suponiendo que el proceso de la evolución humana se produce en el individuo, que vive en la comunidad, se organiza sobre la base de la obra, sometiéndose a las leyes sociales e históricas, este estudio examina la película francesa "El niño salvaje (L'enfant sauvage), de 1969, cuya narración es guiada en la historia real del descubrimiento, en 1797, de un niño de edad comprendida entre los 11 y 12, que no mostró rastros de contacto con la sociedad humana. En este sentido, teniendo en cuenta la relación establecida entre los procesos de aprendizaje y desarrollo, sistema en una situación muy inusual de aislamiento social total, hemos tratado de reflexionar sobre las dificultades y los avances realizados por el médico Jean Marc Itard, en relación con el proceso de reeducación del "niño salvaje" en busca de definir, a la luz de la teoría históricocultural, los factores determinantes en el proceso de la evolución humana y el desarrollo cognitivo del niño, analizando la influencia de la interacción social y el papel de la educación en este proceso.

Palabras claves: Evolución humana. Educación. Cultura.
The wild boy: the influence of social interaction and the role of education in cognitive development

\section{Abstract}

Based on the understanding that the process of human evolution occurs to the degree that the individual, living in community, is organized on the basis of work, submitting to social and historical laws, this study examines the French film " L'enfant sauvage, [The Wild Boy] 1969, whose narrative is based on the true story of the discovery in 1797 of a boy between 11 and 12 who showed no traces of contact with human society. In this sense, considering the relationship established between the processes of learning and development, set in a highly unusual situation of total social isolation, we attempted to reflect on the difficulties and progress reported by the physician Jean Marc Itard, in relation to the reeducation of the "wild boy", seeking to define, in the light of historical-cultural theory, the determining factors in the process of human evolution and cognitive development of the boy, analyzing the influence of social interaction and the role of education in this process.

Keywords: Human evolution. Education. Culture. 
Tatiane Marina dos Anjos Pereira

E-mail: tma.rp@hotmail.com

Maria Terezinha Bellanda Galuch

E-mail: mtbgaluch@uem.br

Recebido em: 3/6/2011

Versão final recebida em: 16/3/2012

Aprovado em: 18/4/2012 